\title{
Female Genital Mutilation as Sexual Violence Against Women
}

\author{
Kunthi Tridewiyanti \\ \{kdewitri@gmail.com\} \\ Pancasila University,Jakarta, Indonesia
}

\begin{abstract}
Female circumcision or Female Genital Mutilation or has been practiced in Indonesia and considered as local wisdom and even obligatory, according to religion view. By using doctrinal legal research method written in this inscription, it is mentioned above that circumstance will be examined through a perspective of gender rights, describing genital mutilation as sexual violence and therefore, human rights violation. This paper will discuss two matters. First, explanation of female genital circumcision according to religion, culture, legal and gender views; Second, reasons for female genital mutilation that are considered as sexual violence against women and girls.
\end{abstract}

Keywords: Female Genital Mutilation, Sexual Violence, Women Rights

\section{Introduction}

The practice of female genital mutilation (FGM) still prevails in various places around the world, including in Indonesia. Debates related to the practice of female circumcision continue to occur. Women are still generally experiencing violence based on their gender, and such violence is often defended and legitimized in many parts of the world [1]. Female genital mutilation is generally and vehemently condemned by the international community and becomes global scrutiny which influences the countries in which such practice still exist becomes a national political concern [2]. However, a study conducted by UNICEF stated that the practice of female circumcision has detrimental effects and disadvantageous to women or girls. WHO and UNICEF both consider it as a violation of the rights of children and women and call it as a Female Genital Mutilation (FGM) or Female Genital Cutting (FGC)[3]. In 2012, the UN General Assembly adopted a resolution calling on the international community to end the practice of female circumcision or FGM[4]. Female genital mutilation (FGM) comprises all procedures that involve partial or total removal of the external female genitalia, or another injury to the female genital organs for non-medical reasons. Even in September 2015, the global community approves a new set of development goals, Sustainable Development Goals (SDGs) including targets to eliminate harmful practices, such as child marriages, forced marriages, and $\mathrm{FGM} / \mathrm{C}$ by 2030.[5]Female genital mutilation is classified into 4 major typed (WHO) Type 1: Often referred as clitoridectomy i.e. a partial or total removal of the clitoris (a small, sensitive and erectile part of the female genitals), and in very rare cases, only the prepuce (the fold of skin surrounding the clitoris). Type 2: Often referred as excision, i.e., partial or total removal of the clitoris and the labia minora (the inner folds of the vulva), with or without excision of the labia majora (the outer folds of skin of the vulva). Type 3: Often referred to as infibulations, i.e., narrowing of the vaginal opening through the creation of a covering seal. The seal is formed by cutting and repositioning the labia minora, or labia majora, sometimes through stitching, with or without removal of the clitoris (clitoridectomy). Type 
4: This includes all other harmful procedures to the female genitalia for non-medical purposes, e.g., pricking, piercing, incising, scraping, and cauterizing the genital area.

\section{Methodology}

The research method used in this paper is the doctrinal method which comes from written sources or literature study in the form of primary, secondary, and tertiary legal materials. [6]Therefore, the data are mostly secondary data in which legal texts, statutes, conventions, and literature are the primary source.

\section{Findings}

First, the practice of FGM in terms of religion, culture, and law, both in internationally and nationally scopes of view.

\subsection{Religion}

Some religious leaders claim that Islam adheres to circumcision practice, or circumcision is compulsory for men but not mandatory for women. However, Indonesian Council of Ulama (MUI) has issued Decision of Fatwa of Indonesian Ulama Council Number 9A Year 2008 on Law of Prohibition of Circumcision against Women. One of the considerations of issuing this fatwa is due to the rejection by some of the Indonesia society and community against female circumcision and request for a fatwa to MUI that was filed by the Ministry of Women Empowerment and Child Protection as well. In providing publicly legal assurance, MUI considers the needs to enact a fatwa on the prohibition of circumcision against women. While the Decree of the 27th National Conference of Tarjih Muhammadiyah 2010 regarding Female Circumcision, mentioned that: First, circumcision is the male and female genitals wound for the benefit and good deed. Second, male circumcision is required and compulsory due to religious demands and to maximize the function of all male reproductive organs. Third, since female circumcision can reduce women's reproductive rights, it is then, not recommended. Religion certainly plays a role in the shaping of gender and sexual roles through the compelling promise of marital happiness. [7]

\subsection{Culture}

UNICEF data of 2016 shows that Indonesia has taken third place in the world of practicing $\mathrm{FGM} / \mathrm{FGC}$.

Figure 1.

The prevalence of FGM/C among young girls is highest in Gorontalo province and lowest in East Nusa Tenggara

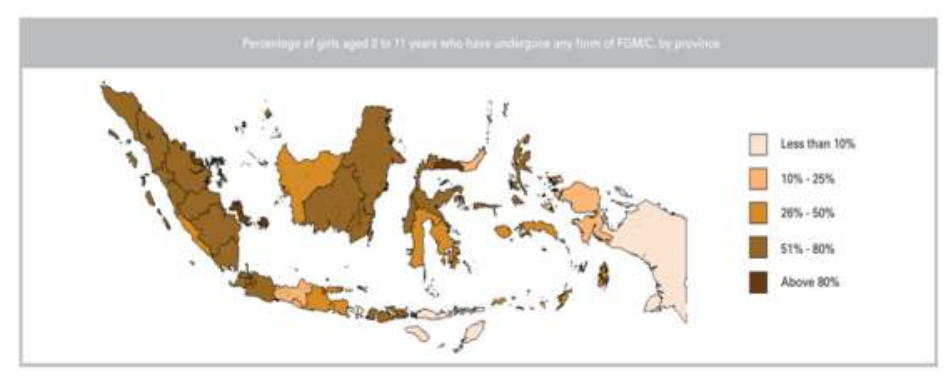


Female circumcision occurs in various regions in Indonesia, but most of this practice occurs in Gorontalo, and the lowest rank is in East Nusa Tenggara. Type I (called the clitoridectomy) and the less invasive procedure (type IV) are the two common types of circumcision practice.

In some regions in Indonesia, the practice of female circumcision is usually done by the parents/guardian or community to infants. The girls have never been asked for the consent of FGM/FGC, which is showing that other people control the women's body.

The negative impacts of FGM/FGC practice are the injury, wound or damage in female genitals cannot be reversed back just as it used to be and women will bear this injury until the rest of their lives, and that there are no health benefits of the practice. Another myth states that women must be circumcised, and several perceived stigmas of being uncircumcised women are flirtatious female, who are unable to uphold purity and chastity, and ones who will bring disgrace to their families [8]. The practice of FGM/FGC causes physical violence (the method of clitoral cutting will result in vaginal bleeding), psychical violence (continuing and prolonged psychological trauma for women, due to stigma and shame, stigma as a bad woman), and sexual violence (clitoral cuts impacted the removal of female sexual pleasure).[8]

\subsection{Rules related to Female Genital Mutilation}

First, the FGM-related rules are still perceived as a violation of the women's rights to health and highly gender bias. As an example, the Ministry of Health has issued a Regulation on Female Circumcision No: 1636/MENKES/PER/XI/2010 dated November 15,2010 . Through this rule, health workers are affirmed on behalf of the safety and security of circumcised women. This regulation in no way affirms the prohibition of female circumcision. Instead, it becomes a guideline for the implementation of health workers to perform female circumcision. This is considered to be a setback from the Government Circular Letter through the Ministry of Health of 2006 issuing the Prohibition on the Medicalization of Female Circumcision for Health Officers, numbered: HK.00.07.1.3.1047a.

Second, FGM is considered as sexual violence against women.

a. FGM/FGC practices that injure and cut the clitoris are considered as a form of discrimination and violence, especially to women, as contained in:

- Article 1 CEDAW: For the purposes of the present Convention, the term "discrimination against women" shall mean any distinction, exclusion, or restriction made on the basis of sex which has the effect or purpose of impairing or nullifying the recognition, enjoyment, or exercise by women, irrespective of their marital status, on a basis of equality of men and women, of human rights and fundamental freedoms in the political, economic, social, cultural, civil, or any other field.

- Article 2 UN Declaration on the Elimination on the Elimination 'Violence against women' means any act of gender-based violence that results in, or is likely to result in, physical, sexual or psychological harm or suffering to women, including threats of such acts, coercion or arbitrary deprivation of liberty, whether occurring in public or in private life.' (UN Declaration on the Elimination of Violence against Women, Article 1) 
b. FGM/FGC practices targeting female genitals by removing body parts related to sexual satisfaction and security may result in violation of the right to physical and mental health as contained in Article 12 of the ICESCR stating "The States Parties to the present Covenant recognize the right of everyone to the enjoyment of the highest attainable standard of physical and mental health".

\subsection{Solution}

Concluding the provision of The United Nations Committee on the Elimination of All Forms of Discrimination Against Women (CEDAW Committee) of 2007 recommending that Indonesia develop an action plan for the elimination of the slightest destructive practice. It is because FGM, including the implementation of campaigns public awareness, is intended to alter the cultural perceptions tied to it and to provide education that incorporates such practices as violations of the human rights of women and girls and has no basis in religion.

National Commission on Violence against Women as a woman rights commission refers to FGM/FGC as culture-based violence against women and girls, especially the physical, psychological, and sexual violence. Sexual violence is an act of insulting, attacking, using a person's body and sexuality by force or threat of violence or other acts so as to cause a person to be unable to give their consent and approval, that cause or will cause misery or physical, psychological and sexual suffering and economic, social, cultural and/or political losses.

FGM/FGC is a sexual control because of the imposition of traditional practices targeting sexuality. Sexual control is a forced or non-consensual act committed by taking over the victim's decision on her body so that the victim cannot make any decisions of her own or her body for the occurrence of marriage, pregnancy, abortion, sterilization and sexual enjoyment without the consent of the victim.

Sexual violence should be abolished and this is the proposal for the nomenclature of the legal Drafting on the Elimination of Sexual Violence, which is promoted to National Legislation Program: Abolition of sexual violence is an attempt to prevent the occurrence of sexual violence including repeated violence, handling, protecting and restoring victims of sexual violence and cracking down and rehabilitating perpetrators of sexual violence

\section{Conclusion}

First, the practice of FGM/FGC is one form of sexual violence against women, since the practice occurs based on religious, cultural and legal interpretations, which still lack the perspective of human rights and Gender. It is, therefore, important that the practice of FGM/FGC should be abolished.

Second, FGM/FGC as sexual violence against women and girls. Therefore there should be an effort to eliminate FGM/FGC by conducting studies, awareness-raising, and advocacy to create a Legal Draft on the Elimination of Sexual Violence.

Third, the State creates a binding regulation on the Elimination of Sexual Violence to prevent and eliminate $\mathrm{FGM} / \mathrm{FGC}$. In addition to increasing the understanding for the caregivers of interest, i.e., parents, traditional/religious figures and law enforcement officials to eliminate FGM/FGC, as it is sexual violence and should be abolished. 


\section{References}

[1] Lakatos I 2018 Thoughts on Universalism versus Cultural Relation with Special Attention to Women's Rights Pecs Journal of International and European Law 1 p. 6

[2] Boyle EH \&Preves S E 2000 National Politics as International Process: The Case of AntiFemale-Genital-Cutting Laws Law \& Society Review 34(3) p. 703-37

[3] UNICEF 2016Female Genital Mutilation/Cutting: A Global Concern

[4] UNICEF 2013Female Genital Mutilation/Cutting: A statistical overview and exploration of the dynamics of change

[5] UNICEF 2016Statistical Profile on Female Genital Mutilation/Cutting: Indonesia

[6] Hutchinson T \& Duncan N J 2012 Defining and Describing What We Do: Doctrinal Legal Research Deakin Law Review 17(1) p. 83-119

[7] Razak A A 2009 Understanding Legal Research Integration \& Dissemination

[8] Utz-Billing I 2008 Female Genital Mutilation: an Injury, Physical and Mental Harm Journal of Psychosomatic Obstetrics \& Gynecology 29 p. 225-9 